anales de psicología / annals of psychology

2019, vol. $35, \mathrm{n}^{\circ} 3$ (october), 472-482

http://dx.doi.org/10.6018/analesps.35.3.323101
(C) Copyright 2019: Editum. Servicio de Publicaciones de la Universidad de Murcia. Murcia (Spain) ISSN print edition: 0212-9728. ISSN on line edition (http://revistas.um.es/analesps): 1695-2294.

On line edition License Creative Commons 4.0: BY-NC-ND

\title{
Unpleasant past experience as a determinant of cognitive, behavioral and physiological responses to academic stress in professional examination candidates
}

\author{
Jesús de la Fuente-Arias ${ }^{1,2, *}$, and Jorge Amate-Romera ${ }^{2}$ \\ 1 University of Navarra (Spain) \\ 2 University of Almeria (Spain)
}

\begin{abstract}
Título: La experiencia desagradable como determinante de las respuestas cognitivas, conductuales y fisiológicas de estrés académico en universitarios opositores.

Resumen: Esta investigación estableció las relaciones de interdependencia y predicción entre experiencia desagradable previa y creencias irracionales, ansiedad evaluativa, autorregulación en el estudio y estrés académico, variables de la competencia para rendir en contextos de alta exigencia. Participaron 221 aspirantes de academias preparatorias a la función pública del cuerpo de Maestros. Las variables fueron medidas mediante autoinformes validados. El diseño fue ex post-facto lineal, con análisis inferenciales y estructurales. Los resultados mostraron relaciones significativas positivas de interdependencia de la experiencia desagradable con las creencias irracionales y respuestas fisiológicas de estrés, así como negativas con la autorregulación en el estudio. Además, apareció una relación estructural predictiva significativa entre experiencia desagradable y respuestas cognitivas, conductuales y fisiológicas de estrés. Estos resultados validan parcialmente las relaciones del modelo CAERE, explicando el aprendizaje en contextos estresantes, y evidencian la necesidad de entrenar a los estudiantes ante estas situaciones.

Palabras clave: modelo CAERE; creencias irracionales; ansiedad evaluativa; autorregulación en el estudio; estrés académico.
\end{abstract}

\section{Introduction}

In many countries, public employment is attained through selective examinations. This implies preparing for and taking one or several tests in competition with hundreds of thousands of aspirants. In present-day Spain, to become a public school teacher, one must complete written exams that measure technical knowledge, and oral exams, where job-related skills and aptitudes are assessed. Preparation for this type of test requires sustained, high productivity; it is a complex task that involves persistent, self-regulated use of different competencies (Koivuniemi, Panadero, Malmberg \& Järvelä, 2017). Some of these competencies relate to the nature of the tests themselves, while others have to do with controlling emotions and one's own learning process in this type of context (Gómez \& Gundín, 2016).
Abstract: This investigation established unpleasant past experience in interdependent and predictive relations with irrational beliefs, test anxiety, selfregulated study and academic stress, variables belonging to the competency for performing in highly demanding contexts. Participants were 221 candidates enrolled in preparatory academies, where they were preparing for competitive exams for posts as public elementary school teachers. The variables were measured using validated self-reports. A linear, ex postfacto design was used, with inferential and structural analyses. Unpleasant experience was shown to have significant, positive, interdependent relations with irrational beliefs and physiological stress responses, as well as negative relations with self-regulated study. Significant, predictive, structural relations were found between unpleasant experience and cognitive, behavioral, and physiological stress responses. These results partially validate the relationships shown in the SLPS Competency model, which explains learning in stressful contexts; and offer evidence of the need to train students for these situations.

Keywords: SLPS Competency model; irrational beliefs; test anxiety; selfregulated study; academic stress.

\section{The SLPS Competency Model, for Studying, Learn- ing, and Performing under Stress (de la Fuente, 2015; de la Fuente et al., 2014), as a research heuris- tic}

This model explains learning in highly demanding contexts and establishes three dimensions of this competency: knowing (facts, concepts and principles), know-how (study skills and meta-skills, instrumental skills, self-regulation strategies and coping strategies) and finally, mindset (attitudes, values and habits related to studying and to the selection process). These dimensions and the variables that form them are related to each other in multiple ways. Moreover, they interact with other variables that appear previously or later on. These variables are shown in Figure 1, organized according to Biggs' 3P Model of Presage, Process, Product (Biggs, 2001); the $3 \mathrm{P}$ model has been confirmed in many research studies (Barattucci, Pagliaro, Cafagna \& Bosetto, 2017). The SLPS Competency Model has appeared in recent Educational Psychology research (Contreras, 2015), although it requires further empirical validation. This model is founded on more than a decade of prior evidence of the interference between stress and cognitive and motivational processes during learning and study (Serlachius, Hamer \& Wardle, 2007), and of the influence of aspects such as test anxiety and irrational beliefs on stress, thereby contributing to demotivation in the learning process (Largo-Wight, Peterson \& Chen, 2005). Based on a definition of the stress response during learning
* Correspondence address [Dirección para correspondencia]:
Dr. Jesús de la Fuente Arias. Facultad de Educación y Psicología. Universidad de Navarra. Campus Universitario s/n, 31009 Pamplona (Spain). Email: jdlfuente@unav.es

(Article received: 28-02-2018; revised: 28-3-2018; accepted: 31-3-2019) 
as a complex, multidimensional process, with cognitive, physiological, emotional and behavioral indicators (Arsenio \& Loria, 2014; de la Fuente et al., 2014; Romero, Master,
Paunesku, Dweck, \& Gross, 2014), this model seeks to incorporate all these aspects in order to evaluate their impact on academic stress.

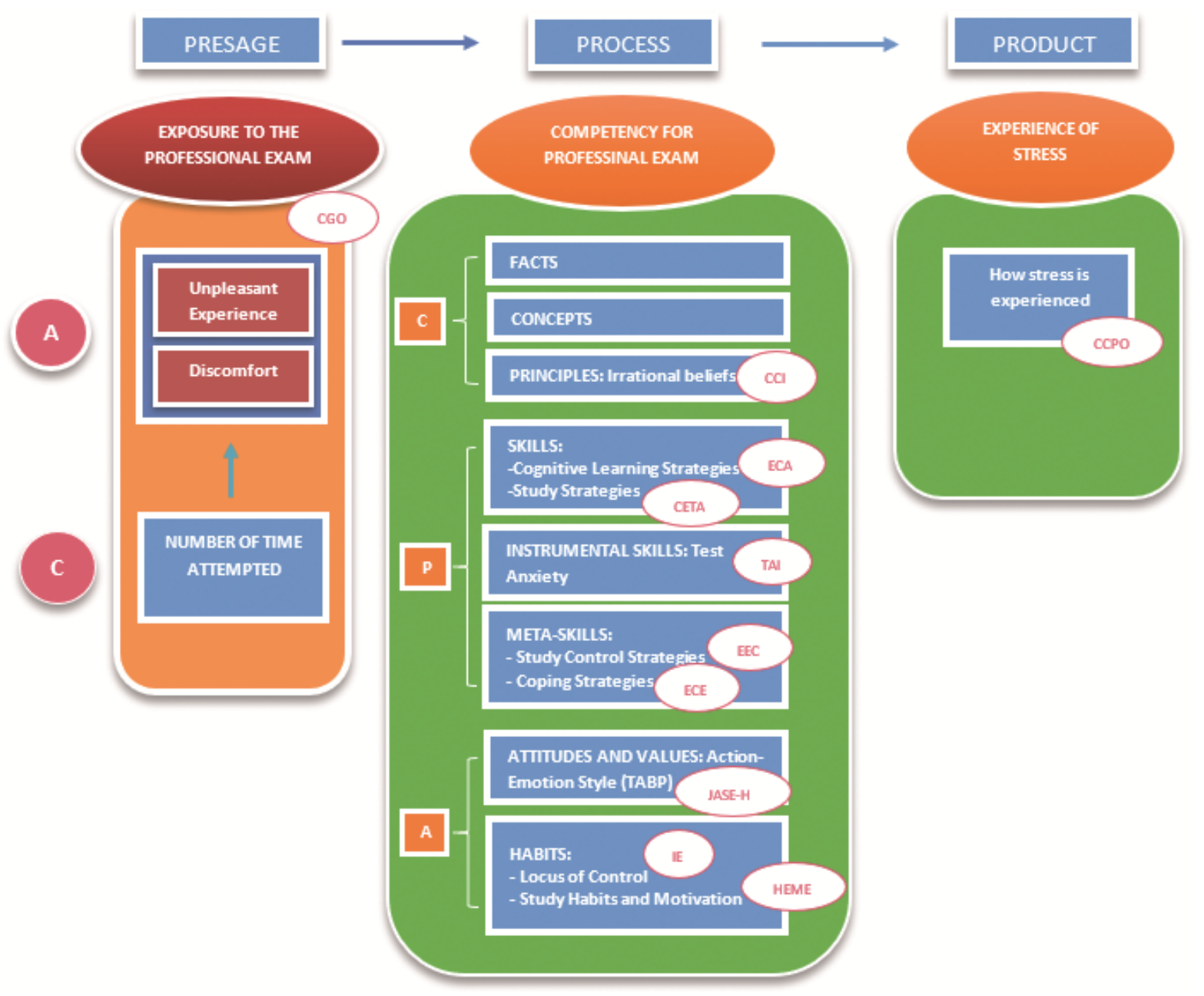

Figure 1. The SLPS Competency Model (de la Fuente, 2015) with variables and some of the instruments used. Initials shown in red refer to the abbreviated names of the instruments used for measuring the adjacent variable; each of these are defined above in the corresponding section on instruments used.

\section{Unpleasant experience as a presage variable}

This variable is understood as the student's negative assessment of his/her past experience with professional exams, as well as his or her present situation and future outlook. The influence of prior experience on performance has already been studied in other spheres (Alanzi, 2015).

\section{Irrational beliefs as a process variable}

Irrational beliefs are explanatory, cognitive elaborations about real events, that (1) lack evidence to support them, and (2) make no contribution to problem solving (Malhotra \& Kaur, 2016). Subjects who are prone to irrational beliefs usually persevere in them rigidly even when they know that their beliefs are irrational and negative (Wessler, Hankin, \& Stern,
2016). These beliefs may have a good deal of influence on the learning process and on academic stress, as recent studies indicate (Keshu, Thomas \& Dey, 2016).

\section{Test anxiety as a process variable}

Test anxiety has been thoroughly researched in past decades and is consistently associated with problems in learning and performance, since it involves a substantial loss in cognitive resources (Putwain, Daly, Chamberlain \& Sadreddini, 2015). Studies indicate that there are sizable student populations whose levels of anxiety are cause for concern (Álvarez, Aguilar \& Lorenzo, 2012). This anxiety has two components: worry and emotionality (Burdwood et al., 2016), referring to cognitive aspects and to emotional manifestations, respectively (Pekrun \& Stephens, 2012). 


\section{Self-regulated study as a process variable}

This refers to meta-skills that the student uses to control and direct his or her own learning process (Bembenutty, Cleary \& Kitsantas, 2014). Research has shown that students who practice self-regulated learning are more motivated to keep up their effort in learning, an essential aspect of preparing for job placement exams, and that the variable of selfregulation predicts performance (Zimmerman \& Kitsantas, 2014). Furthermore, other studies have associated selfregulation strategies with variables like anxiety and stress (Zhang, 2013).

\section{Academic stress as a product variable: cognitive and physiological correlates}

Unlike in the clinical sphere (Costarelli \& Patsai, 2012), educational research has not given proper attention to the stress response, although more articles are appearing in recent years (Mehmet \& Watson, 2017). While stress in general is defined as an adaptive response when facing a threat, academic stress fundamentally pertains to perceived aspects such as loss of control over outcomes, arbitrariness of the grading system, demands of the situation and a lack of competence for studying and learning in stressful contexts (de la Fuente et al., 2014). Notwithstanding, academic stress has been shown to have substantial influence in certain cognitive processes, like memory and attention, and in motivational aspects (Serlachius, Hamer \& Wardle, 2007). On the other hand, anxiety associated with stress can also increase thoughts of worry and negative emotionality, considerably expanding negative thoughts and irrational beliefs, and diminishing motivation (Karaman \& Watson, 2017). De la Fuente et al. (2014) proposes that anxiety be assessed based on the correlates of stress, both cognitive (interfering thoughts) and physiological (level of activation). These correlates are considered product variables in the present research.

\section{Objectives and hypotheses}

The aim of this investigation is to add to the scientific evidence that helps us understand the complex relations involved in preparing for these tests, and to equip professionals with tools for intervention. The general objective was to describe the interdependent and predictive relationships that were most significant and important among the variables evaluated (identified above). In accordance with the scientific basis for these variables, the bypotheses were formulated as follows:

1) The variable unpleasant experience (presage) will demonstrate interdependence relationships with the variables $i r$ rational beliefs, test anxiety and self-regulated study strategies (process).

2) The variables irrational beliefs, test anxiety and self-regulated study strategies (process) will be interdependent with each another.

3) The variable unpleasant experience (presage), as well as the variables irrational beliefs, test anxiety and self-regulated study strategies (process), will demonstrate interdependence relationships with the cognitive and physiological correlates of academic stress (product).

4) The variable unpleasant experience (presage) will jointly and significantly predict: (1) positively, cognitive variables of irrational beliefs and interfering thoughts; (2) negatively, the behavioral variable of self-regulated study; and (3) positively, the emotional variable of test anxiety and physiological stress.

\section{Method}

\section{Participants}

A total of 221 professional examination candidates participated. All of them were enrolled in preparatory academies to prepare the exams for Primary School Teacher in Almería province (Spain). The selection method was random and nonprobabilistic; first, five preparatory academies in the province were selected, then the groups within each academy were also randomly selected and finally the participating subjects. No further inclusion or exclusion criteria were applied when forming our sample. Experimental mortality was less than $5 \%$ over the duration, and for reasons outside the scope of the research study, such as dropping out of the academy during the research process. We must note that not all subjects were able to answer all the questionnaires, since they were administered in different class sessions, and not all subjects were in attendance at every session. Cases with incomplete data were eliminated from the study. Given the characteristics of the population that usually prepares for these exams, the sample was mostly female $(n=161)$. Ages ranged from 21-45 years $(M=24.02 ; S D=4.99)$. All participants had completed the undergraduate university degree in Primary Education, and approximately $20 \%$ had also completed a Master's program. Most participants were in their first year of exam preparation $(n=133)$, while very few had exceeded five years in preparation $(n=12)$. All subjects had Spanish nationality, and most of them had completed their degree at University of Almería.

\section{Instruments}

Cuestionario General del Opositor, CGO [General Questionnaire for the Exam Candidate] (de la Fuente et al., 2014)

This was used to measure the presage variable: Unpleasant experience. It contains 7 items on a 4-point response scale, and assesses not only past experiences with professional examinations, but also perception of the current and future situation, and the resulting degree of affectedness. After being subjected to confirmatory factor analysis, the structure of the instrument contained two factors: Factor 1, past experi- 
ence, comprising a total of 5 items; and Factor 2, present-future experience, composed of 2 items. Construct validity is acceptable (Chi-squared $=80.051, d f=13$, NFI Delta $1=$ $0.931, \mathrm{RFI}=0.911, \mathrm{IFI}=0.941, \mathrm{TLI}=0.912, \mathrm{CFI}=0.941$, RMSEA $=0.087)$, with acceptable indicators in relation to adequate sample size (HOELTER $.05=152$, HOELTER $.01=189)$. Total questionnaire reliability is also acceptable $(\alpha=.738)$.

\section{Cuestionario de Creencias Irracionales, CCI [Irrational Beliefs questionnaire] (de la Fuente et al., 2014)}

This was used to measure the process variable by the same name. It is composed of 20 items which represent typical statements about the professional examination, where the candidate must score his or her level of agreement on a scale of 0 to 4 . These statements refer to the most common irrational beliefs, according to the specialists: Oughts (e.g. "I ought to have passed these examinations a long time ago"), Catastrophizing (e.g. "If I fail it would be so awful for me"), and overgeneralizations (e.g. "Almost all the panels of judges are unfair"). After being submitted to confirmatory factor analysis, the structure of the instrument is composed of two factors and twelve items, given that the remaining items were not sufficiently consistent: Factor 1, anticipation of failure, comprising a total of 4 items; and Factor 2, negative general assessments, composed of 8 items. Construct validity is acceptable $($ Chi-squared $=148.071, d f=53$, NFI Delta $1=0.909$, $\mathrm{RFI}=0.924$, IFI $=0.908, \mathrm{TLI}=0.914, \mathrm{CFI}=0.914)$, and high according to some indicators (RMSEA $=0.057$, HOELTER $.05=261$, HOELTER $.01=294)$. Total questionnaire reliability is also adequate $(\alpha=.782)$.

\section{TAI-80 (Sarason, 1980)}

The TAI- 80 was used to measure test anxiety, considered a process variable. The inventory contains 20 Likert-type items on a four-point response scale, with expressions commonly used to describe oneself; the subject must answer according to how frequently he or she identifies with these expressions. Confirmatory factor analysis showed a structure comprising two factors and 20 items: Factor 1, worry, comprising a total of 10 items; and Factor 2, emotionality, composed of another 10 items. Construct validity is acceptable (Chi-squared $=524.674, d f=169$, NFI Delta $1=0.917$, RFI $=0.910$, IFI $=0.929$, TLI $=0.913$, CFI $=0.915$, RMSEA $=$ 0.062, HOELTER $.05=208$, HOELTER $.01=223)$. Total questionnaire reliability is also very high $(\alpha=.917)$. These data are similar to what other authors have found using different procedures (de la Fuente, Sander et al., 2017), given that this questionnaire has been widely used in Educational Psychology research.
Inventario de Estrategias de Control Durante el Estudio, ECE (Hernández \& García, 1995) [Inventory of control strategies during study]

This was used to measure self-regulated study strategies, considered a process variable. It is composed of 17 items, in 3 categories according to the time when each strategy is used (at the start of study, during study and at the end of study), and has a five-point response scale. After being submitted to confirmatory factor analysis, the structure of the instrument contains two factors and 14 items, given that the remaining items were not sufficiently consistent: Factor 1, study planning, comprising a total of 7 items; and Factor 2, study process/review, composed of 8 items. Construct validity is adequate $($ Chi-squared $=220.312, d f=76$, NFI Delta $1=0.911$, RFI $=0.931$, IFI $=0.927$, TLI $=0.912$, CFI $=0.914$, RMSEA $=0.059$, HOELTER $.05=241$, HOELTER $.01=$ 266). Total questionnaire reliability is also adequate $(\alpha=$ $.856)$.

Cuestionario de Pensamientos Interferentes sobre la Oposición, CCPO (de la Fuente et al., 2014) QQuestionnaire on Interfering Thoughts about the Professional Exam]

This questionnaire was used to measure the cognitive correlate of academic stress, one of the indicators into which the product variable was divided, for study purposes. It contains 10 items representing common thoughts; the subject must indicate how often he or she experiences them, their intensity, duration, degree of interference and the situation in which they occur. All of these were answered on a four-point scale, except "situation", which required a dichotomous answer (during study or in many situations). Confirmatory factor analysis showed a structure comprising two factors and 10 items: Factor 1, thoughts about maladaptive emotions, comprising a total of 5 items; and Factor 2, thoughts about negative outcomes, composed of another 5 items. Construct validity is consistent (Chi-squared $=90.718, d f=34$, NFI Delta $1=$ $0.902, \mathrm{RFI}=0.928, \mathrm{IFI}=0.905, \mathrm{TLI}=0.914, \mathrm{CFI}=0.915$, RMSEA $=0.055$, HOELTER $.05=292$, HOELTER $.01=$ 337). Total questionnaire reliability is also $\operatorname{good}(\alpha=.820)$.

Inventario de Vivencias de Tensión y Ansiedad, IVTAO (de la Fuente et al., 2014) [nventory of tension and anxiety experiences]

This was used to measure the physiological correlate of academic stress, another indicator of the product variable. It has 20 items, representing different physiological responses during study; responses were on a four-point scale according to the degree of intensity with which the subject experienced them. Confirmatory factor analysis revealed a structure comprising six factors and 20 items: Factor 1, tension, comprising a total of de 6 items; Factor 2, sweating, composed of 2 items; Factor 3, trembling, composed of 3 items; Factor 4, nausea, composed of 2 items; Factor 5, movements, composed of 4 items; and finally, Factor 6, rapid heartbeat, composed of 3 
items. Construct validity is acceptable (Chi-squared = 339.256, $d f=163$, NFI Delta $1=0.880$, RFI $=0.913$, IFI $=$ 0.940, TLI $=0.917$, CFI $=0.902$, RMSEA $=0.045$, HOELTER $.05=311$, HOELTER $.01=334)$. Total questionnaire reliability is also acceptable $(\alpha=.732)$.

\section{Procedure}

The instruments were used in written format. Although the time interval for test administration was reduced as much as possible, several weeks were required, given the number of instruments, frequency of class sessions at the academies, and limitations of the research itself, thus resulting in a certain amount of experimental mortality during the investigation. In order to minimize contaminating external factors, questionnaires were administered in a normal class situation; the usual teacher explained the study objectives and their importance, without going into details or hypotheses. Participants were guaranteed confidentiality at all times and were asked to answer truthfully and individually. At the end of the investigation, participating subjects were given feedback from the overall study as well as individualized feedback, and were thanked for their participation.

Data was compiled and processed on a voluntary basis, with the informed consent of the students. The Ethical and Deontological Principles of Psychology were accepted. Data were processed in an anonymous format and as a group, and stored in a protected database at the university. The Bioethics Committee approved the Project and the instruments.

\section{Data analyses}

An ex post facto design was used for this research study, given that the groups formed from the sample for independ- ent variables were not intentionally selected, but rather formed according to the score obtained in these variables after the questionnaires were administered. At Time 1, inferential analyses (ANOVA) were carried out. The level $p<.05$ was considered for significant effects. Low-medium-high levels were previously established according to scores on different variables, using $\mathrm{k}$-means clustering analysis. Post hoc tests were performed using the Sheffe index. These analyses and the validity and reliability indicators (Cronbach alpha) were carried out using SPSS v.22. The AMOS program (v.22) was also used for SEM analyses and to analyze instrument structure through confirmatory factor analysis.

\section{Results}

\section{Interdependence relations between presage and process variables}

The low-medium-high level of IV unpleasant experience determined a significant main effect on the dependent variable negative general assessments, one of the two factors of the irrational beliefs variable $\left[F(2,51)=3.278, p<.05, n^{2}=.114\right.$, observed power $=.598$; Post hoc: $1<3, p<.05]$. A significant main effect was also found on the variable self-regulated study strategies $\left[F(2,115)=4.093, p<.01, n^{2}=.066\right.$, observed power $=.716$; Post hoc: $1>3, p<.05]$; and its two factors, study planning $\left[F(2,218)=3.206, p<.05, n^{2}=.029\right.$, observed power $=.608]$ and study process $/$ review $[F(2,140)=4.239, p<$ $.01, n^{2}=.057$, observed power $=.734$; Post hoc: $1>2,3, p<$ .05]. See Table 1.

Table 1. Interdependence relations between presage and process variables.

\begin{tabular}{lccc}
\hline & \multicolumn{3}{c}{ Unpleasant experience } \\
& Low (1) & Medium (2) & High (3) \\
$n=67$ & $n=97$ & $n=57$ \\
\hline Negative general assessments (v. irrational beliefs, F2) & $2.05(.71)$ & $2.25(.65)$ & $2.63(.69)$ \\
Self-regulated study strategies (total variable) & $4.05(.55)$ & $3.78(.50)$ & $3.70(.60)$ \\
Study planning (v. self-regulated study strategies, F1) & $3.92(.62)$ & $3.70(.56)$ & $3.70(.60)$ \\
Study Process/Review (v. self-regulated study strategies, F2) & $3.94(.60)$ & $3.62(.62)$ & $3.59(.68)$ \\
\hline
\end{tabular}

Note: Interdependence relationships between some process variables and their factors (DV) and the level of unpleasant experience (IV). Mean and standard deviation are indicated for each group; only the variables or factors with significant effects are shown $(p<.05)$.

\section{Interdependence relations between process varia-} bles

The low-medium-high level of IV irrational beliefs produced a significant main effect on the dependent variable test anxiety $\left[F(2,55)=2.990, p<.05, n^{2}=.098\right.$, observed power=.558]; and its two factors, worry $[F(2,63)=3.981, p<.05$, $n^{2}=.112$, observed power $=.693$; Post hoc: $\left.1<3, p<.05\right]$ and emotionality $\left[F(2,60)=3.372, p<.05, n^{2}=.101\right.$, observed power $=.615$; Post hoc: $1<3, p<.05]$. See Table 2 .

When the low-medium-high levels of test anxiety were taken as an independent variable, there was a significant main effect on the dependent variable negative general assessments, one of the two factors of the irrational beliefs variable $[F$ $(2,56)=9.984, p<.001, n^{2}=.263$, observed power $=.980$; Post hoc: $1<3, p<.001 ; 2<3, p<.05]$. Similarly, the independent variable test anxiety was observed in an interdependence relation with the dependent variable self-regulated study strategies $\left[F(26,0)=3.760, p<.05, n^{2}=.111\right.$, observed power $=.665$; Post hoc: $1>2, p<.05$ ], as well as with the study planning factor $\left[F(2,61)=4.550, p<.05, n^{2}=.130\right.$, observed power $=.754$; Post hoc: $1>2, p<.05 ; 2<3, p<.05]$. See 
Table 2.

Table 2. Interdependence relations between process variables.

\begin{tabular}{|c|c|c|c|}
\hline & \multicolumn{3}{|c|}{ Irrational beliefs } \\
\hline & $\begin{array}{c}\text { Low (1) } \\
n=27\end{array}$ & $\begin{array}{c}\text { Medium (2) } \\
n=33\end{array}$ & $\begin{array}{c}\text { High (3) } \\
n=10\end{array}$ \\
\hline Test anxiety (total variable) & $2.19(.72)$ & $2.43(.57)$ & $2.85(.66)$ \\
\hline Worry (v. test anxiety, F1) & $1.94(.65)$ & $2.22(.57)$ & $2.63(.55)$ \\
\hline \multirow[t]{3}{*}{ Emotionality (v. test anxiety, F2) } & $2.38(.77)$ & $2.58(.60)$ & $3.11(.74)$ \\
\hline & \multicolumn{3}{|c|}{ Test anxiety } \\
\hline & $\begin{array}{c}\text { Low }(1) \\
n=26\end{array}$ & $\begin{array}{c}\text { Medium (2) } \\
n=16\end{array}$ & $\begin{array}{c}\text { High (3) } \\
K=25\end{array}$ \\
\hline Negative general assessments ( $v$. irrational beliefs, F2) & $1.95(.55)$ & $2.15(.47)$ & $2.74(.72)$ \\
\hline Self-regulated study strategies (total variable) & $3.98(.62)$ & $3.43(.68)$ & $3.94(.59)$ \\
\hline Study planning ( $v$. self-regulated study strategies, F1) & $4.04(.76)$ & $3.34(.77)$ & $3.98(.64)$ \\
\hline
\end{tabular}

Note: Interdependence relationships between some process variables and their factors (DV) and the level of irrational beliefs and test anxiety (IV). Mean and standard deviation are indicated for each group; only the variables or factors with significant effects are shown $(p<.05)$.

Interdependence relations between the presage-process variables and the product variable

The low-medium-high level of IV Unpleasant experience, showed a significant main effect on the dependent variable maladaptive thoughts, one of the two factors of the cognitive correlates of academic stress $\left[F(2,33)=3.363, p<.05, n^{2}=\right.$ .169 , observed power $=.594$; Post hoc: $1<3, p<.05]$. See Table 3.

On the other hand, when low-medium-high levels of irrational beliefs were taken as an independent variable, a significant effect was observed on the dependent variable academic stress-cognitive correlates $\left[F(2,21)=3.379, p<.05, n^{2}=.243\right.$, observed power $=.573]$, and on its factor thoughts about negative outcomes $\left[F(2,26)=3.712, p<.05, n^{2}=.222\right.$, observed power $=.628]$. Likewise, this independent variable was observed to have a significant effect on the dependent variable academic stress-physiological correlates $\left[F(2,24)=5.218, p<.05, n^{2}=.303\right.$, observed power $=.780$; Post hoc: $1<3, p<.01 ; 2<3$, $p<.05]$, and on its factors sweating $[F(2,43)=6.982, p<.01$, $n^{2}=.245$, observed power $=.908$; Post hoc: $1,2<3, p<$ $.01]$, trembling $\left[F(2,40)=3.728, p<.05, n^{2}=.157\right.$, observed power $=.650$; Post hoc: $1<3, p<.05]$ and movements $[F(2$,
$30)=4.578, p<.01, n^{2}=.234$, observed power $=.733$; Post hoc: $1<3, p<.05]$. See Table 3 .

On the other hand, when taking low-medium-high levels of test anxiety as independent variable, a significant effect was observed on the dependent variable academic stress-cognitive correlates $\left[F(2,27)=5.341, p<.01, n^{2}=.283\right.$, observed power=.796; Post hoc: $1<2,3, p<.05]$, and on its factors thoughts about maladaptive emotions $\left[F(2,29)=6.880, p<.01, n^{2}=.322\right.$, observed power $=.893$; Post hoc: $1<2,3, p<.01]$ and thoughts about negative outcomes $\left[F(2,38)=3.074, p<.05, n^{2}=\right.$ .139 , observed power $=.559]$. Likewise, this independent variable was observed to have a significant effect on the dependent variable rapid heartbeat, one of the factors of the variable academic stress-physiological correlates $[F(2,39)=$ $6.287, p<.01, n^{2}=.244$, observed power $=.873$; Post hoc: 1 $<3, p<.01 ; 2<3, p<.05$ ]. See Table 3 .

Finally, when taking low-medium-high levels of selfregulated study strategies as independent variable, a significant effect was observed on the dependent variable nausea, one of the factors of the variable academic stressphysiological correlates $\left[F(2,40)=3.423, p<.05, n^{2}=.146\right.$, observed power $=.610$; Post hoc: $1>2, p<.05]$. See Table 3.

Table 3. Interdependence relations between presage-process variables and product variables.

\begin{tabular}{|c|c|c|c|}
\hline & \multicolumn{3}{|c|}{ Unpleasant experience } \\
\hline & $\begin{array}{c}\text { Low (1) } \\
n=10\end{array}$ & $\begin{array}{c}\text { Medium (2) } \\
n=10\end{array}$ & $\begin{array}{c}\text { High (3) } \\
n=18\end{array}$ \\
\hline \multirow[t]{3}{*}{ Maladaptive emotions/thoughts (v. academic stress: cognitive corr., F1) } & $2.03(.51)$ & $2.32(.38)$ & $2.48(.42)$ \\
\hline & \multicolumn{3}{|c|}{ Irrational beliefs } \\
\hline & $\begin{array}{c}\text { Low (1) } \\
n=21\end{array}$ & $\begin{array}{c}\text { Medium (2) } \\
n=17\end{array}$ & $\begin{array}{c}\text { High (3) } \\
n=10\end{array}$ \\
\hline Academic stress: cognitive corr. (total variable) & $2.03(.32)$ & $2.42(.38)$ & $2.56(.54)$ \\
\hline Thoughts about negative outcomes (v. academic stress: cognitive corr., F2) & $2.17(.43)$ & $2.57(.42)$ & $2.73(.50)$ \\
\hline Academic stress: physiological corr. (total variable) & $1.34(.36)$ & $1.45(.24)$ & $1.89(.21)$ \\
\hline Sweating (v. academic stress: physiological corr., F2) & $1.21(.40)$ & $1.18(.30)$ & $1.75(.46)$ \\
\hline Trembling (v. academic stress: physiological corr., F3) & $1.14(.30)$ & $1.31(.41)$ & $1.75(1.00)$ \\
\hline Movements $(v$. academic stress: physiological corr., F5) & $1.48(.39)$ & $1.68(.53)$ & $2.25(.50)$ \\
\hline
\end{tabular}




\begin{tabular}{|c|c|c|c|}
\hline & \multicolumn{3}{|c|}{ Test anxiety } \\
\hline & $\begin{array}{c}\text { Low (1) } \\
n=17\end{array}$ & $\begin{array}{c}\text { Medium (2) } \\
n=10\end{array}$ & $\begin{array}{c}\text { High (3) } \\
n=19\end{array}$ \\
\hline Academic stress: cognitive corr. (total variable) & $2.02(.46)$ & $2.57(.18)$ & $2.46(.38)$ \\
\hline Thoughts about maladaptive emotions (v. academic stress: cognitive corr., F1) & $1.82(.51)$ & $2.49(.20)$ & $2.36(.42)$ \\
\hline Thoughts about negative outcomes (v. academic stress: cognitive corr., F2) & $2.21(.49)$ & $2.52(.35)$ & $2.58(.43)$ \\
\hline \multirow[t]{3}{*}{$\underline{\text { Rapid heartbeat ( } v \text {. academic stress: physiological corr., FO) }}$} & $1.23(.39)$ & $1.20(.36)$ & $1.93(.91)$ \\
\hline & \multicolumn{3}{|c|}{ Self-regulated study strategies } \\
\hline & $\begin{array}{c}\text { Low (1) } \\
n=10\end{array}$ & $\begin{array}{c}\text { Medium (2) } \\
n=14\end{array}$ & $\begin{array}{c}\text { High (3) } \\
n=19\end{array}$ \\
\hline Nausea (v. academic stress: physiological corr., F4) & $1.70(.59)$ & $1.14(.31)$ & $1.39(.59)$ \\
\hline
\end{tabular}

\section{Structural linear relations (SEM)}

The results of structural analysis or path analysis (SEM) showed an acceptable model of variable relations. Values for the models tested are presented below. See Table 4.

Standardized direct effects. The predictive linear model establishes that the latent variable unpleasant experience (F1) was a significant positive predictor (.708) of the latent cognitive variable irrational beliefs (F2). Moreover, the irrational beliefs varia- ble (F2) was a positive predictor (.896) of the latent variable academic stress-cognitive correlates (F5). In the same way, the latent variable unpleasant experience (F1) was a significant negative predictor $(-.220)$ of the latent behavioral variable selfregulated study strategies $(\mathrm{F} 4)$. At the same time, the latent variable unpleasant experience (F1) was a positive predictor (.53) of test anxiety (F3), and test anxiety (F3) appeared in a significant, positive predictive relationship (.456) with the latent variable academic stress-physiological correlates (F6). See Table 5.

Table 4. Structural linear relations models.

\begin{tabular}{lllllllllll}
\hline & Chi2 & FG & $p<$ & NFI & RFI & IFI & TLI & CFI & HOELTER & RMSEA \\
\hline Model & 544.804 & $(299-81): 218$ & .000 & .806 & .709 & .876 & .869 & .873 & .444 & .078 \\
Model & 112.931 & $(119-46): 73$ & .002 & .903 & .916 & .920 & .917 & .915 & .502 & .032 \\
\hline
\end{tabular}

Table 5. Standardized direct effects.

\begin{tabular}{lllllll}
\hline & F1 & F2 & F3 & F4 & F5 & F6 \\
\hline F2 & .708 & & & & & \\
F3 & .534 & & & & & \\
F4 & -.220 & & & & &
\end{tabular}

F5 $\quad .896$

F6

CGOFACTOR1 $\quad .647$

CGOFACTOR2 $\quad .573$

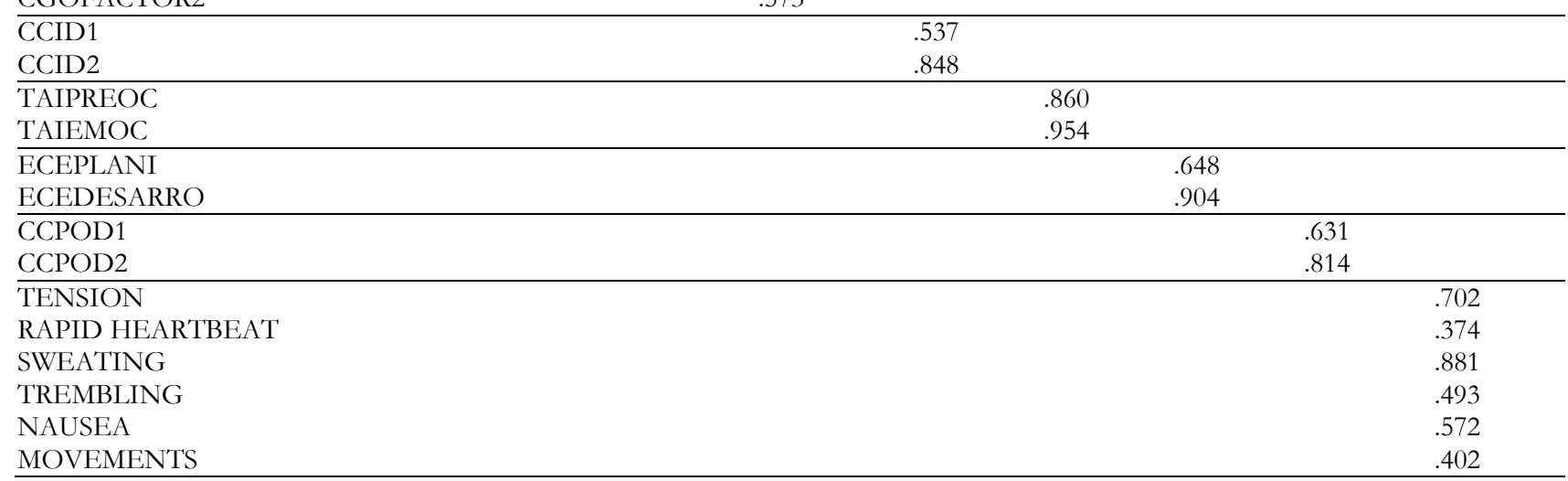

Note: F1= Unpleasant experience; F2= irrational beliefs; F3=Test anxiety; F4=Self-regulated study; F5= academic stress-cognitive correlates; F6 $=$ academic stress-physiological correlates

Standardized indirect effects. The model also showed multiple indirect predictions between variables. The predictive linear model established that the latent variable unpleasant experience (F1) was a significant positive predictor (.634) of the latent 
variable academic stress-cognitive correlates (F5), and a positive predictor (.224) of the latent variable academic stress-physiological correlates (F6). Additionally, the latent variable unpleasant experience (F1) held a positive, indirect predictive relationship with the components of test anxiety (F3), academic stress-cognitive corre- lates (F5) and academic stress-physiological correlates (F6). Howev$\mathrm{er}$, it had an indirect, negative effect on the latent variable self-regulated study strategies (F4). See Table 6. See the graphic representation of the model in Figure 2.

Table 6. Standardized indirect effects.

\begin{tabular}{llllll} 
F1 & F2 & F3 & F4 & F5 & F6 \\
\hline
\end{tabular}

\section{F2}

F3

F4

F5

F6 $\quad .244$

CGOFACTOR1

CGOFACTOR2

CCID1

CCID2

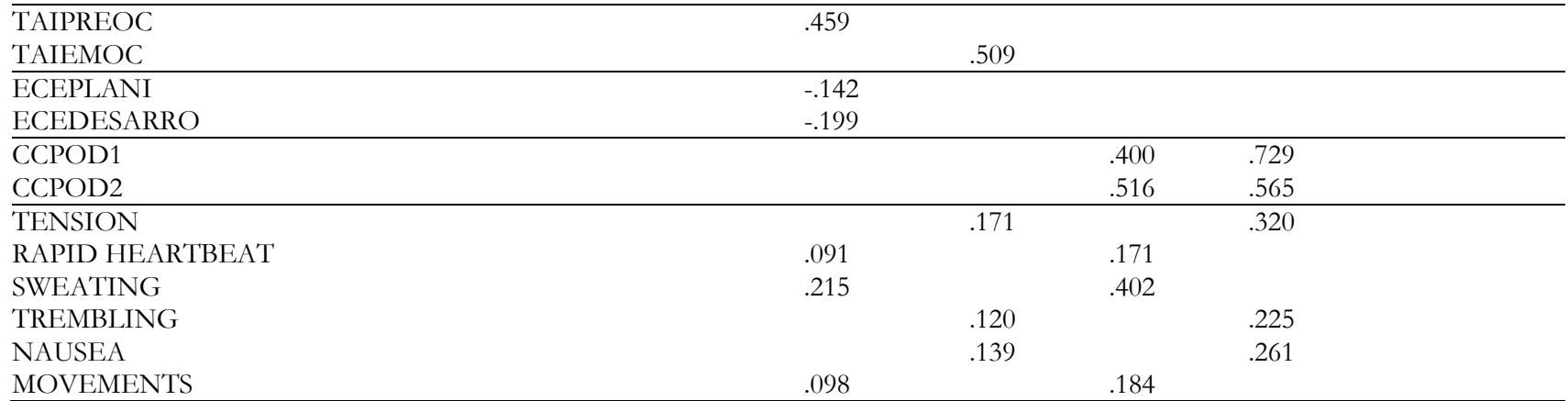

Note: $\mathrm{F} 1=$ unpleasant experience; $\mathrm{F} 2=$ irrational beliefs; $\mathrm{F} 3=$ test anxiety; $\mathrm{F} 4=$ self-regulated study; $\mathrm{F} 5=$ academic stress-cognitive correlates; $\mathrm{F} 6=$ academic stress-physiological correlates

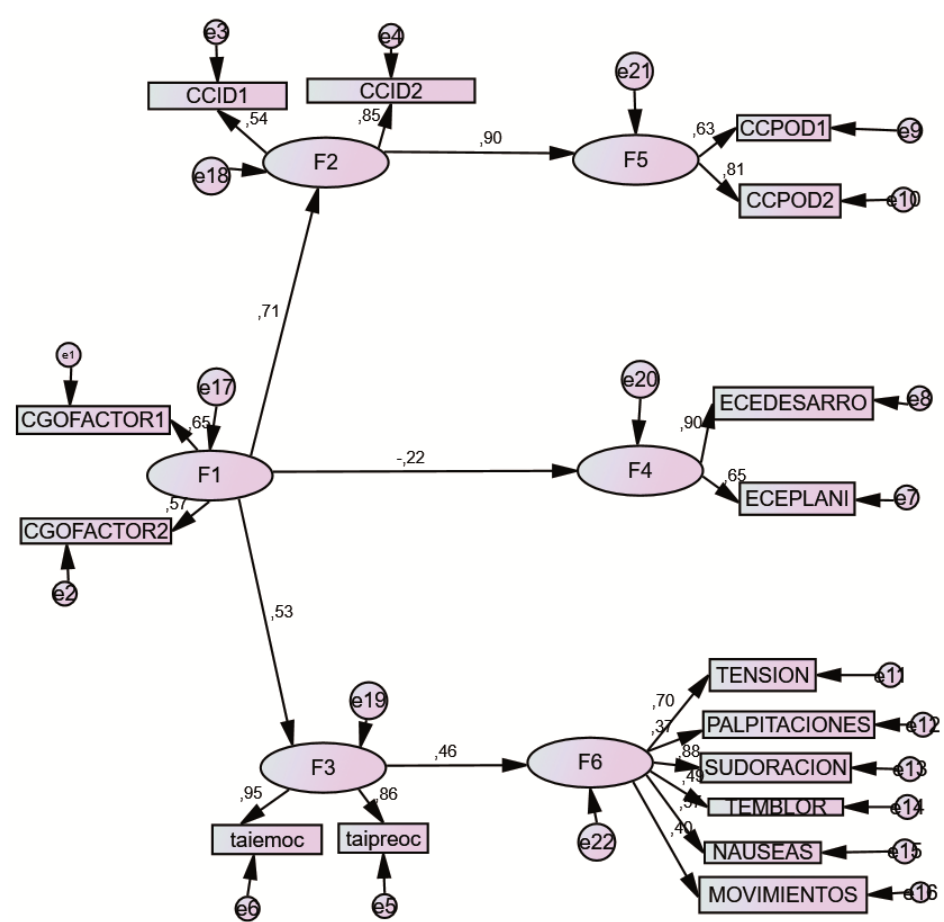

Figure 2. Graphic representation of the structural model.

F1 = Unpleasant experience; F2= irrational beliefs; F3=Test anxiety; F4=Self-regulated study; F5= academic stress-cognitive correlates; F6= academic stress-physiological correlates. PALPITACIONES: rapid heartbeat. SUDORACION: sweating. TEMBLOR: trembling. NAUSEAS: nausea. MOVIMIENTOS: movements. 


\section{Discussion and Conclusions}

The results indicated that there were significant interdependence and structural prediction relationships among the research variables, partially validating the relationships proposed in the SLPS Competency model for predicting study behavior in stressful situations.

In more detail, Hypothesis 1 was partially fulfilled, providing evidence that previous experience determines different process variables and factors in the system, and therefore constitutes an important factor to be considered in preparing for these exams. Nonetheless, in the case of irrational beliefs, this relationship was only observed in one of its factors, and with respect to the test anxiety variable, no interdependence relationship was observed at all. As for its important relationship to self-regulation strategies and its two factors, unpleasant experience probably acts by reducing tolerance to frustration, leading subjects to exercise fewer strategies, or less-developed strategies (Akfirat, Gül \& Yetim, 2016). This would explain why the effect between the variables unpleasant experience and self-regulation strategies is less intense in the final period of study (review) than it was initially (planning), thereby giving rise to new hypotheses which can be empirically tested.

Hypothesis 2 was also partially validated. While irrational beliefs and test anxiety are strongly interdependent, and test anxiety is also interdependent with self-regulated study strategies, no such relationship is appreciable between the irrational beliefs variable and self-regulated study strategies, something which must be examined in greater depth (Cheng \& Liao, 2016). The relationship between irrational beliefs and anxiety is sufficiently well understood, it is not for naught that anxiety has an important cognitive component (Pedroza, 2015). Yet to be verified is its relationship to other external variables that recent research has identified, such as locus of control, which might actively contribute to the origin and maintenance of many irrational beliefs and of test anxiety (Senler, 2016).

Regarding Hypothesis 3, it was also partially validated. While interdependence relations between presage/process variables and academic stress can be observed, on several occasions this only occurred when considering the cognitive correlates of academic stress, and not its physiological correlates. Along this line, results indicate that physiological correlates of stress depend to a greater degree on the level of irrational beliefs than on the level of test anxiety, despite an $a$ priori inclination to attribute a greater component of physiological activation to test anxiety (Leung, Yeung \& Wong, 2010).

Finally, Hypothesis 4, referring to structural relations, is consistently validated. A relationship structure consistent with the role of unpleasant experience was confirmed; there was a clear, three-fold effect -- cognitive, behavioral and physiological -- on how professional examination candidates study. These results are consistent with prior evidence that show the importance of initial experiences for continuing universi- ty-level studies, when diverse variables are considered (García, Gutiérrez \& Rodríguez-Muñiz, 2016).

As for general limitations of this study, in addition to those mentioned above, there is a need to study the role of gender. Because of limitations in the present sample, it would be desirable to replicate this study with a greater number of participants and better representation of both genders; test results cannot be extrapolated to the general population, since they may be influenced by the clearly higher number of women than men. Regarding gender influence, earlier research shows significant differences between the sexes in test-related stress and in anxiety (Kosmala-Anderson \& Wallace, 2007). Regarding sample representativeness, we should note that all the subjects in this study were preparing for the exams at an academy; this same research could also have included candidates who prepare on their own, and so compare the two groups and verify whether there were significant differences between them.

\section{Implications in Educational Psychology}

The most important implication of these results is the need to take greater interest and intervene preventively in the explanations that subjects make when they interpret their experiences with preparing this type of selective examination. In this way, the subject can come to attribute more realistic meanings and avoid simplistic explanations that trigger states of anxiety or stress, which in the end make it more difficult to reach the final objective of obtaining a post. This area of interest could be incorporated into the exam preparatory process itself, making it a process of wholistic educational care for the candidate, not merely intellectual or test preparation. Lastly, it could be embodied as a specific program for preventing academic stress, such as is proposed in the SLPS Competency Model (de la Fuente, 2015). Recent studies, also carried out with samples of university students pursuing the Primary Education degree, show that there are effective techniques for easing levels of academic stress and test anxiety (Gallego, Aguilar-Parra, Cangas, Rosado \& Lánger, 2016). In addition, certain tools of interest have incorporated a clear component of ICT innovation, and are available for coping with stress in relation to highly demanding tests (de la Fuente, 2015).

\section{Future lines for research}

Given that there is limited research on this topic in Educational Psychology, and in light of the potential of the underlying theoretical model used in this investigation, the possibilities for future studies are numerous and diverse. One could look for relations with other model variables that have not been analyzed in this investigation, such as instrumental skills involved in the tests, or motivational strategies (Busari, 2017), and also include stronger evidence on the possible causal relationships that may exist between the variables 
studied, in line with other recent reports (de la Fuente, Fernández-Cabezas et al., 2017).

\section{References}

Akfirat, S., Gül, A., \& Yetim, Ü. (2016). Interrelations among Regulation Focus, Authenticity and Emotional Responses to Frustration of SelfRelated Experiences among University Students in Turkey. Current $P_{s y}$ chology, 35(1), 99-107. doi: 10.1007/s12144-015-9370-6

Alanzi, K. A. (2015). Does previous collegiate academic experience affect students' performance? International Journal of Education Economics and Development, 6(4), 303-313. doi: 10.1504/IJEED.2015.075793

Álvarez, J., Aguilar, J. M., \& Lorenzo, J. J. (2012). La ansiedad ante los exámenes en estudiantes universitarios: Relaciones con variables personales y académicas [Test Anxiety in University Students: Relationships with Personal and Academic Variables]. Electronic Journal of Research in Educational Psychology, 10(1), 333-354. Retrieved from http://www.investigacion-psicopedagogica.org

Arsenio, W. F., \& Loria, S. (2014). Coping with negative emotions: connections with adolescents' academic performance and stress. J Genet Psychol, 175(1-2), 76-90. doi: 10.1080/00221325.2013.806293

Barattucci, M., Pagliaro, S., Cafagna, D., \& Bosetto, D. (2017). An examination of the Applicability of Biggs' 3P Learning Process Model to Italian University. Journal of e-Learning and Knowledge Society, 13(1), 163-180. doi: 10.20368/1971-8829/1277

Bembenutty, H., Cleary, T. J., \& Kitsantas, A. (2014). Applications of SelfRegulated Learning across Diverse Disciplines: A Tribute to Barry J. Zimmerman. Charlote, NC: Information Age Publishing, Inc. Retrieved from http://www.infoagepub.com

Biggs, J. (2001). Teaching for Quality Learning at University. Buckingham, England: Open University Press. Retrieved from https://www.researchgate.net

Burdwood, E. N., Infantolino, Z. P., Crocker, L. D., Spielberg, J. M., Banich, M. T., Miller, G. A., \& Heller, W. (2016). Resting-state functional connectivity differentiates anxious apprehension and anxious arousal. Psychophysiology, 53(10), 1451-1459. doi: 10.1111/psyp.12696

Busari, A. O. (2017). The relationship between personality types, learning styles, motivation, self-esteem and academic stress among distance learners in Ibadan Study Center. International Journal of Innovation and Applied Studies, 19(4), 850-862. Retrieved from http://www.ijias.issrjournals.org

Cheng, P. Y., \& Liao, W. R. (2016). The Relationship Between Test Anxiety and Achievement in Accounting Students with Different Cognitive Styles: The Mediating Roles of Self-Regulation. International Research in Education, 4(2), 14-33. doi: 10.5296/ire.v4i2.9177

Contreras, M. C. (2015). Resiliencia, estrategias de afrontamiento y enfoques de aprendiraje, como aspectos de la competencia aprender a aprender con estrés en el contexto de enseñanza-aprendizaje universitario [Resilience, coping strategies, learning approaches, as aspects of the learning-to-learn-with-stress competency, in the context of university teaching-learning 7 (Doctoral dissertation). University of Granada, Spain. Retrieved from https://www.educacion.gob.es/teseo

Costarelli, V., \& Patsai, A. (2012). Academic examination stress increases disordered eating symptomatology in female university students. Eat Weight Disord, 17(3), 164-169. doi: 10.1007/BF03325343

de la Fuente, J. (2015). Competency for studying, learning and performing under stress: Selfhelp guide for University Students, Graduates and Professional Examination Candidates. Almería: Education \& Psychology $\mathrm{I}+\mathrm{D}+\mathrm{i}$. Retrieved from http://www.mitienda.investigacion-psicopedagogica.org

de la Fuente, J., Fernández-Cabezas, M., Cambil, M., Vera, M. M., González-Torres, M. C., \& Artuch-Garde, R. (2017). Linear relationship between resilience, learning approaches, and coping strategies to predict achievement in undergraduate students. Frontiers in Psychology, 8:1039. doi: 10.3389/fpsyg.2017.01039

de la Fuente, J., López, M., Zapata, L., Martínez-Vicente, J. M., Mariano, M., Solinas, G., \& Fadda, S. (2014). Competency to study and learn in
Acknowledgments.- R\&D Project EDU2011-24805, PGC2018094672-B-I00 (Ministry of Science and Education, Spain), and UAL18-SEJ-DO31-A-FEDER (University of Almería), and the European Social Fund.

stressful contexts: fundamentals of the "e-Coping with Academic Stress" utility. Electronic Journal of Research in Educational Psychology, 12(3), 717-746. doi: 10.14204/ejrep.34.14034

de la Fuente, J., Sander, P., Martínez-Vicente, J. M., Vera, M., Garzón, A. \& Fadda, S. (2017). Combined Effect of Levels in Personal SelfRegulation and Regulatory Teaching on Meta-Cognitive, on MetaMotivational, and on Academic Achievement Variables in Undergraduate Students. Frontiers in Psychology, 8, 1-19. doi:10.3389/fpsyg.2017.00232

Gallego, J., Aguilar-Parra, J. M., Cangas, A., Rosado, A., \& Lánger, A. (2016). Efecto de intervenciones mente/cuerpo sobre los niveles de ansiedad, estrés y depresión en futuros docentes de educación primaria: Un estudio controlado [Effect of mind/body interventions on levels of anxiety, stress and depression in future primary education teachers. A controlled study]. Revista de Psicodidáctica, 21(1), 1-13. doi: 10.1387/RevPsicodidact.13256

García, M. E., Gutiérrez, A. B. B., \& Rodríguez-Muñiz, L. J. (2016). Permanencia en la universidad: la importancia de un buen comienzo [Staying in college: the importance of a good start]. Aula Abierta, 44(1), 1-6. doi: $10.1016 /$ j.aula.2015.04.001

Gómez, C. M. V., \& Gundín, O. A. (2016). Estresores académicos percibidos por estudiantes universitarios y su relación con el burnout y el rendimiento académicos [Academic stressors perceived by university students and their relation to burnout and academic achievement]. Anuario de Psicología, 46(2), 90-97. doi: 10.1016/j.anpsic.2016.07.006

Hernández, P., \& García, L. A. (1995). Proyecto HERGAR [The HERGAR Project]. Unpublished document, University of La Laguna, Spain.

Karaman, M. A., \& Watson, J. C. (2017). Examining associations among achievement motivation, locus of control, academic stress, and life satisfaction: A comparison of US and international undergraduate students. Personality and Individual Differences, 111, 106-110. doi: 10.1016/j.paid.2017.02.006

Keshu, M., Thomas, S., \& Dey, A. M. (2016). Cognitive and cultural aspects of academic stress: a review. International Education and Research Journal, 2(1), 80-85. Retrieved from http://www.ierj.in

Koivuniemi, M., Panadero, E., Malmberg, J., \& Järvelä, S. (2017). Higher education students' learning challenges and regulatory skills in different learning situations. Infancia y Aprendizaje, 40(1), 1-37. doi: 10.1080/02103702.2016.1272874

Kosmala-Anderson, J., \& Wallace, L. M. (2007). Gender differences in the psychosomatic reactions of students subjected to examination stress. Electronic Journal of Research in Educational Psychology, 5(2), 325-348. Retrieved from http://www.investigacion-psicopedagogica.org

Largo-Wight, E., Peterson, P. M., \& Chen, W. W. (2005). Perceived problem solving, stress, and health among college students. Am J Health Behav, 29(4), 360-370. doi: 10.5993/AJHB.29.4.8

Leung, G., Yeung, K. C., \& Wong, D. (2010). Academic Stressors and Anxiety in Children: The Role of Paternal Support. Journal of Child and Famiby Studies, 19, 90-100. doi: 10.1007/s10826-009-9288-4

Malhotra, N., \& Kaur, R. (2016). Examining the relationship of irrational beliefs with social-emotional skills. Indian Journal of Health and Wellbeing, 7(7), 714-716. Retrieved from http://iahrw.com

Mehmet, A. K., \& Watson, J. C. (2017). Examining associations among achievement motivation, locus of control, academic stress, and life satisfaction: A comparison of U.S. and international undergraduate students. Personality and Individual Differences, 111(1), 106-110. doi: 10.1016/j.paid.2017.02.006

Pedroza, R. (2015). Reeducación cognitiva-emotiva en caso de ansiedad ante los exámenes [Cognitive-emotional reeducation in the case of test 
anxiety]. Revista Iberoamericana para la Investigación y el Desarrollo Educativo, 6(11), 319-335. Retrieved from http://www.ride.org.mx

Pekrun, R., \& Stephens, E. J. (2012). Academic emotions. In K. R. Harris, S. Graham, T. Urdan, S. Graham, J. M. Royer, \& M. Zeidner (Eds.), APA handbooks in psychology. APA educational psychology bandbook, Vol. 2. Individual differences and cultural and contextual factors (pp. 3-31). Washington, DC: American Psychological Association. doi: 10.1037/13274-001

Putwain, D., Daly, A., Chamberlain, S., \& Sadreddini, S. (2015). Academically buoyant students are less anxious about and perform better in high-stakes examinations. British Journal of Educational Psychology, 85(3), 247-263. doi: 10.1111/bjep.12068

Romero, C., Master, A., Paunesku, D., Dweck, C. S., \& Gross, J. J. (2014). Academic and emotional functioning in middle school: The role of implicit theories. Emotion, 14(2), 227-234. doi: 10.1037/a0035490

Sarason, I. G. (1980). Test anxiety: Theory, research and application. Hillsdale, N.J.: Erlbaum.
Senler, B. (2016). Pre-service science teachers' self-efficacy: The role of attitude, anxiety and locus of control. Australian Journal of Education, 60(1), 26-41. doi: 10.1177/0004944116629807

Serlachius, A., Hamer, M., \& Wardle, J. (2007). Stress and weight change in university students in the United Kingdom. Physiol Behav., 92(4), 548553. doi: $10.1016 /$ j.physbeh.2007.04.032

Wessler, R. Hankin, S., \& Stern, J. (2016). Trabajando con clientes difíciles. Aplicaciones de la Terapia de Valoración Cognitiva [Working with difficult customers: Applications of Cognitive Assessment Therapy]. Bilbao: Desclée De Brouwer. Retrieved from https://www.edesclee.com

Zhang, X. (2013). Stress, coping, and depression in adolescents: A longitudinal analysis of data from national longitudinal study of adolescent health (Doctoral dissertation). University of Nebraska, NE. Retrieved from http://digitalcommons.unl.edu/cehsdiss/185

Zimmerman, B. J., \& Kitsantas, A. (2014). Comparing students' selfdiscipline and self-regulation measures and their prediction of academic achievement. Contemporary Educational Psychology, 39(2), 145-155. doi: 10.1016/j.cedpsych.2014.03.004 